\title{
Optimization of Reduced Glutathione Production by a Lactobacillus plantarum Isolate Using Plackett-Burman and Box-Behnken Designs
}

\author{
Lamiaa A. Al-Madboly ${ }^{1 *}$, Eman G. Khedr ${ }^{2}$ and Safaa M. Ali ${ }^{3}$ \\ 'Department of Pharmaceutical Microbiology, Faculty of Pharmacy, Tanta University, Tanta, Egypt, ${ }^{2}$ Department of \\ Biochemistry, Faculty of Pharmacy, Tanta University, Tanta, Egypt, ${ }^{3}$ Department of Nucleic Acid Research, Genetic \\ Engineering and Biotechnology Research Institute, City for Scientific Research and Technology Applications, Alexandria, \\ Egypt
}

\section{OPEN ACCESS}

Edited by:

Cheng-Hsien Liu,

National Tsing Hua University, Taiwan

Reviewed by:

Seung Gu Shin

Pohang University of Science and Technology, South Korea

Aindrila Mukhopadhyay,

Lawrence Berkeley National

Laboratory, USA

*Correspondence:

Lamiaa A. Al-Madboly

lamia.youssif@pharm.tanta.edu.eg

Specialty section:

This article was submitted to Microbiotechnology, Ecotoxicology

and Bioremediation,

a section of the journa

Frontiers in Microbiology

Received: 19 April 2016 Accepted: 13 April 2017

Published: 09 May 2017

Citation:

Al-Madboly LA, Khedr EG and

Ali SM (2017) Optimization of Reduced Glutathione Production by a Lactobacillus plantarum Isolate Using Plackett-Burman

and Box-Behnken Designs.

Front. Microbiol. 8:772.

doi: 10.3389/fmicb.2017.00772
In this work, we aim to optimize the production of reduced glutathione (GSH) synthesized intracellularly by a food-grade microorganism through a statistical approach. Using a colorimetric method, 25 Lactobacillus plantarum isolates were screened in an attempt to find a GSH-producing strain. It was found that $36 \%$ of the tested isolates showed positive result. Isolate $\left(L_{7}\right)$ was found to produce 152.61 $\mu \mathrm{M}$ glutathione per gram which was the highest amount produced intracellularly. Accordingly, the later isolate was selected for the optimization process using PlackettBurman and Box-Behnken designs. Temperature, amino acids, and urea were found to be the most significant independent variables. Following data analysis, the composition of the optimized medium was De Man-Sharp-Rogosa broth as a basal medium supplemented with $\mathrm{NaCl}(5 \%), \mathrm{H}_{2} \mathrm{O}_{2}(0.05 \%)$, sodium dodecyl sulfate $(0.05 \%)$, amino acids $(0.0281 \%)$, and urea $(0.192 \%)$. The $\mathrm{pH}$ of the medium was adjusted to 8 and incubated for $24 \mathrm{~h}$ at $40^{\circ} \mathrm{C}$. The GSH amount was increased by 10 -fold (851\%) using the optimized medium. Hence, our optimization design estimated the biotechnological potential of $L_{\text {. plantarum }}\left(\mathrm{L}_{7}\right)$ for the production of $\mathrm{GSH}$ in the industry.

Keywords: glutathione, L. plantarum, Placket-Burman, Box-Behnken, optimization

\section{INTRODUCTION}

Glutathione is a tripeptide thiol composed of $\gamma$-glutamylcysteinylglycine (GSH) which is found in all eukaryotes and some prokaryotes such as probiotics. GSH is involved in many physiological processes and the general functions can be summarized in three ways, i.e., GSH serves as an antioxidant, an immunity booster, and a detoxifier in eukaryotes. First, the strong electrondonating capability of GSH and the relatively high intracellular concentration enable the maintenance of a reducing cellular environment. This makes GSH an important antioxidant for protecting DNA, proteins and other biomolecules against oxidative damage produced by reactive 
oxygen species. Second, GSH has potent antiviral activity in addition to the enhancement of immunity. Finally, GSH is significant in detoxification reactions via glutathione- $S$ transferase. Thus, GSH is a powerful defense molecule generated in prokaryotes and eukaryotes (Halliwell and Gutteridge, 1992; Pastore et al., 2003).

Different strategies have been developed to maintain high cellular levels of GSH. The most common strategy is the administration of GSH or its precursors. One innovative approach is the consumption of living microorganisms known as probiotics, i.e., live dietary supplements possibly administering specific health benefits to the host. Some probiotics have antioxidative systems to maintain free radicals below toxic levels (Farr and Kogoma, 1991). Glutathione production was detected among yeast (Saccharomyces cerevisiae and Candida utilis) as well as lactic acid bacteria, including Bifidobacterium, Lactobacillus casei HY2782, L. acidophilus ATCC 4356, L. plantarum, L. fermentum, Lactococcus lactis spp. cremoris, Streptococcus thermophiles, Leuconostoc mesenteroides spp. cremoris, Lc. lactis spp. lactis, micrococci, and pediococci in concentrations ranging from $6 \mathrm{nmol} / \mathrm{g}$ to $51 \mu \mathrm{mol} / \mathrm{g}$. How different media types and cellular growth phases affect the intracellular levels of GSH have been also reported in the literature (Murata and Kimura, 1982; Fernandes and Steele, 1993; Li et al., 2004; Yoon and Byun, 2004).

Glutathione can be produced either enzymatically or by fermentation. Currently, the most important method used for industrial production is the fermentation using yeast such as $S$. cerevisiae or C. utilis. Some additional work addressing GSH production in bacteria has been conducted. For example, glutamylcysteine synthetase variants that were desensitized for GSH feedback inhibition had been isolated and cloned, resulting in higher GSH levels. Additionally, Lc. lactis has been used for GSH production even though it has no endogenous GSH (Chi-Hsien et al., 1999; Wei et al., 2003; Li et al., 2004; Masip et al., 2006). Therefore, the development of an industrial fermentation process requires medium optimization and our work is considered to be the first report on the optimization of GSH production using L. plantarum isolate. Optimization using a single variable is not only tedious, but can also lead to misinterpretation of data because of the different interactions that might be overlooked among variables. Statistical optimization allows quick screening for significant variables in a large experimental design while also identifying important roles of each component (Abdel-Fattah et al., 2005; Rathnasabapathy et al., 2009). In our study, we used an integrated statistical approaches incorporating Plackett-Burman and Box-Behnken designs to optimize media components for GSH production by L. plantarum.

\section{MATERIALS AND METHODS}

\section{Test Microorganisms}

Twenty-five L. plantarum isolates were previously collected from fermented milk and identified by API-50CHL (Al-Madboly and Abdullah, 2015).

\section{Screening for the Production of Reduced Glutathione (GSH) among L. plantarum Isolates}

Test isolates were screened for the intracellular GSH using cell lysates.

\section{Preparation of Cell Lysates}

Overnight cultures grown on De Man-Rogosa-Sharpe (MRS) agar at $37^{\circ} \mathrm{C}$ were used to inoculate $50-\mathrm{ml}$ Falcon tubes containing MRS broth and were incubated under anaerobic conditions until log phase. Bacteria were harvested by centrifugation $(5,000 \times g)$ at $4^{\circ} \mathrm{C}$ for $15 \mathrm{~min}$. Next, the pellet was washed twice with phosphate buffered saline (PBS, $\mathrm{pH}$ 7.4) and then re-suspended in PBS. The cell suspension was disrupted using an ultrasonicator (Branson Sonic Power, USA) in an ice bath. Cellular debris was removed by centrifugation $\left(10,000 \times g\right.$ for $10 \mathrm{~min}$ at $\left.4^{\circ} \mathrm{C}\right)$. Following this step, cell lysates were used to quantify total protein content and GSH levels. Each measured parameter represents results obtained from three separate experiments (Zhang et al., 2007).

\section{Determination of GSH Content}

A solution of cold $\left(4^{\circ} \mathrm{C}\right) 320 \mathrm{mM}$ sulfosalicylic acid, $28 \mathrm{mM}$ L-ascorbic acid, and $4 \mathrm{mM}$ EDTA was added to cell lysates for protein precipitation. Precipitated proteins were removed by centrifugation $\left(27,000 \times g, 15 \mathrm{~min}, 4^{\circ} \mathrm{C}\right)$, and the clear supernatants were used to determine the GSH concentration through a GSH assay kit (Biodiagnostics Cat no. TA2511, Egypt) based on the colorimetric method described by Beutler et al. (1963). This reaction depends on the reduction of 5,5' dithiobis (2-nitrobenzoic acid DTNB), which is dissolved in $25 \mathrm{mM}$ PBS, $\mathrm{pH} 7.0$, by the reduced glutathione to give a yellow product measured at $405 \mathrm{~nm}$. GSH contents were expressed as $\mu \mathrm{M}$ of $\mathrm{GSH}$ per gram. Each measurement was repeated in triplicate, the means and standard deviations were calculated.

\section{Molecular Identification of the GSH Over-Producing Isolate}

Identification of the GSH over-producing isolate was further confirmed by $16 \mathrm{~S}$ rRNA gene sequencing. Briefly, growth of an overnight culture at $37^{\circ} \mathrm{C}$ of the selected isolate $\left(\mathrm{L}_{7}\right)$ was used for the preparation of genomic DNA that was extracted using GenJET Genomic DNA purification Kit [Thermo Scientific, (EU) Lithuania] according to the manufacturer's instructions. The target isolate was identified by $16 \mathrm{~S}$ rRNA gene sequencing using universal primers AGAGTTTGATCMTGGCTCAG and TACGGYACCTTGTTACGACTT. The PCR mixture consisted of 10 pmol of each primer, $10 \mathrm{ng}$ of chromosomal DNA, $20 \mathrm{mM}$ dNTPs, and $2.5 \mathrm{U}$ of Taq polymerase in $50 \mu \mathrm{l}$ of polymerase buffer (Fermentas, Germany). The PCR was run for 34 cycles at $94^{\circ} \mathrm{C}$ for $1 \mathrm{~min}, 55^{\circ} \mathrm{C}$ for $1 \mathrm{~min}$, and $72^{\circ} \mathrm{C}$ for $10 \mathrm{~min}$. The $16 \mathrm{~S}$ rRNA gene fragment (1450 bp length) was sequenced. Multiple sequence alignment and molecular phylogeny were performed using BioEdit 7.0.5.3 and TreeViewX. 


\section{Effect of the Growth Phase on the GSH Content of the Selected Isolate}

Glutathione content was determined as previously described in the cell lysate of $L$. plantarum isolate $\left(\mathrm{L}_{7}\right)$ following growth in MRS broth at $37^{\circ} \mathrm{C}$ under anaerobic conditions. Growth curve was prepared by measuring the optical density (OD) of the cells at $660 \mathrm{~nm}$ spectrophotometrically at $0,2,4,6,8,10,24,36,48,60$, and $72 \mathrm{~h}$ in a disposable cuvette (Zhang et al., 2007; Olson and Aryana, 2012).

\section{Optimization of GSH Production Plackett-Burman Screening Design and Statistical Analysis of the Data}

A Plackett-Burman experimental design (Plackett and Burman, 1946) was used to evaluate the significance of multiple media compositions for production of GSH. Fourteen parameters were tested at two levels, -1 for the low and +1 for the high as shown in Table 1, based on a Plackett-Burman matrix design (Table 2). This was representing two level factorial design and allowing the investigation of $n-1$ variables in at least $n$-experiments. In this work, a design matrix with 16 trials was used to study the selected 14 variables (Ali et al., 2013). The PlackettBurman experimental design was based on a first-order model: $\mathrm{Y}=\beta_{0}+\Sigma \beta \mathrm{iXi}$, where $\mathrm{Y}$ is the response (GSH amount), $\beta_{0}$ is the model intercept, $\beta \mathrm{i}$ is the linear coefficient, and $\mathrm{Xi}$ is the level of the independent variable. This model did not describe any interaction among factors, and it was used to determine important factors influencing production of reduced GSH levels.

TABLE 1 | Variables and levels used in Plackett-Burman design for screening of culture conditions affecting glutathione (GSH) production.

\begin{tabular}{|c|c|c|}
\hline Variables & -1 & +1 \\
\hline $\begin{array}{l}\text { - Osmotic stress: sodium } \\
\text { chloride (\%) }\end{array}$ & 1 & 5 \\
\hline \multicolumn{3}{|l|}{ - Oxidative stress: } \\
\hline - Bile salt (\%) & - & 0.5 \\
\hline - Hydrogen peroxide (\%) & - & 0.05 \\
\hline - Urea (\%) & - & 0.1 \\
\hline - Detergent: SDS (\%) & - & 0.05 \\
\hline \multicolumn{3}{|l|}{ - Alcohols: } \\
\hline • Ethanol (\%) & - & 2 \\
\hline - Butanol (\%) & - & 1 \\
\hline - Salts: Potassium chloride (\%) & - & 0.5 \\
\hline $\begin{array}{l}\text { - Incubation under aerobic } \\
\text { conditions }\end{array}$ & - & + \\
\hline $\begin{array}{l}\text { - Precursor amino acids } \\
\text { (equally mixed combination of } \\
\text { glycine, L-cysteine, and } \\
\text { glutamic acid, } 0.05 \% \text { ) }\end{array}$ & - & + \\
\hline$-\mathrm{pH}$ & 6 & 8 \\
\hline - Temperature $\left({ }^{\circ} \mathrm{C}\right)$ & 30 & 40 \\
\hline - Incubation time (h) & 18 & 24 \\
\hline $\begin{array}{l}\text { - Cooling after incubation at } \\
4^{\circ} \mathrm{C}\end{array}$ & - & $24 \mathrm{~h}$ \\
\hline
\end{tabular}

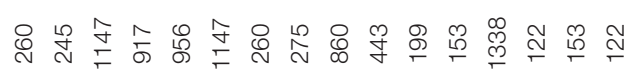

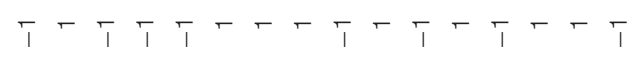

$-T_{1} \tau_{1}-\tau_{1}-\tau_{1}-\tau_{1}$

(2)

(2)

I

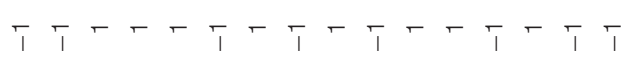

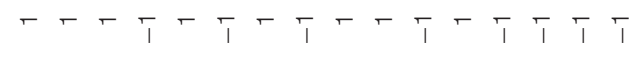

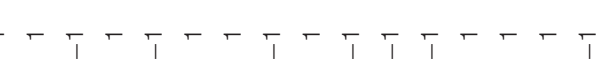


To prepare the optimization media, L. plantarum isolate $\left(\mathrm{L}_{7}\right)$ was grown overnight in MRS agar and inoculated into $500 \mathrm{ml}$ of MRS broth before incubation at $30^{\circ} \mathrm{C}$ for $18 \mathrm{~h}$ until exponential growth reached an OD of approximately 1.2 at $650 \mathrm{~nm}\left(\mathrm{OD}_{660}\right)$. Cells were harvested by centrifugation at $5,000 \times g$ for $15 \mathrm{~min}$, washed twice with $20 \mathrm{mM}$ sterile phosphate buffer, $\mathrm{pH} 7$, standardized to obtain a final $\mathrm{OD}_{660}$ of 2 , and then used to inoculate each trial under test. The trials were prepared as follows: $52 \mathrm{~g}$ of MRS powder was suspended in $1 \mathrm{~L}$ of distilled water and put in a boiling water bath for $10 \mathrm{~min} ; 80 \mathrm{ml}$ was dispensed into $150 \mathrm{ml}$ flasks, and each trial was prepared according to the concentrations mentioned in Table 1 and the matrix designed in Table 2. Flasks were autoclaved except for heat sensitive materials like precursor amino acids that were filter sterilized then added following autoclaving. Each flask was inoculated with the selected isolate then the final volume was completed to $100 \mathrm{ml}$ with sterile MRS broth and incubated either anaerobically in Genbox jars (BioMérieux SA, France) using AnaeroGen bags (Oxoid, England) or aerobically according to Table 2. The GSH data were subjected to statistical analysis, where Essential Experimental Design free software was used for the data analysis, determining the coefficients, and the polynomial model reduction (Steppan et al., 1999).

\section{Box-Behnken Experimental Design and Statistical Analysis of Data}

To describe the nature of the response surface in the experimental region and to identify the optimum conditions for GSH production, a Box-Behnken design was applied (Box and Behnken, 1960). Each significant variable was studied in three levels coded $-1,0$, and +1 for low, middle, and high values, respectively, as recorded in Table 3 . The design matrix consisted of 13 trials was used to study the most significant variables affecting GSH production as shown in Table 4. To predict the optimal point, a second order polynomial function was fitted to correlate the relationship between the independent variables and the response (GSH amount), for three factors. The equation was: $\mathrm{Y}=\beta_{0}+\beta_{1} \mathrm{X}_{1}+\beta_{2} \mathrm{X}_{2}+\beta_{3} \mathrm{X}_{3}+\beta_{12} \mathrm{X}_{1} \mathrm{X}_{2}+\beta_{13} \mathrm{X}_{1} \mathrm{X}_{3}$ $+\beta_{23} X_{2} X_{3}+\beta_{11} X_{1}{ }^{2}+\beta_{22} X_{2}{ }^{2}+\beta_{33} X_{3}{ }^{2}$, where $Y$ is the predicted response, $\beta_{0}$ is the model constant, $\mathrm{X} 1, \mathrm{X} 2$, and $\mathrm{X} 3$, are the independent variables, $\beta_{12}, \beta_{13}$, and $\beta_{23}$ are the cross product coefficients, and $\beta_{11}, \beta_{22}$, and $\beta_{33}$ are the quadratic coefficients. Microsoft Excel 2007 was used for the regression analysis of the experimental data. The quality of fit of the polynomial model equation was expressed by a coefficient of $R^{2}$ determination. Experiments were performed in triplicate, and the mean values are given. The optimal production value was estimated using the Solver function of the Microsoft Excel tools.

\section{RESULTS AND DISCUSSION}

Twenty-five L. plantarum isolates were previously isolated from fermented milk (Al-Madboly and Abdullah, 2015) and screened for intracellular GSH contents. It was found that only 9 out of $25(36 \%)$ L. plantarum isolates were positive for GSH production, meaning that GSH production was strain specific. The range of reduced GSH varied between 12.22 and $152.18 \mu \mathrm{M} / \mathrm{g}$. Interestingly, isolate $\mathrm{L}_{7}$ over-produced GSH (152.18 $\mu \mathrm{M} / \mathrm{g}$ protein) as shown in Figure 1. It is noteworthy that isolate $\mathrm{L}_{7}$ has the highest GSH amount reported for a bacterium (Fernandes and Steele, 1993; Wiederholt and Steele, 1994; Yoon and Byun, 2004; Pophaly et al., 2012).

The selected isolate $\left(\mathrm{L}_{7}\right)$ was confirmed as $L$. plantarum by $16 \mathrm{~S}$ rRNA sequencing. The $16 \mathrm{~S}$ rRNA gene sequence was deposited in the GeneBank under the accession number KU720558. A phylogenetic tree was constructed using the Clustal $\mathrm{X}$ 2.0.11 program $^{1}$, which showed that the $\mathrm{L}_{7}$ isolate is related to L. plantarum with $99 \%$ identity as shown in Figure 2. The timecourse of GSH content along with the biomass measurements of L. plantarum isolate $\left(\mathrm{L}_{7}\right)$ were presented in Figure 3. The highest biomass (2.23) was detected at $24 \mathrm{~h}$ of incubation. Maximal GSH content $(152.61 \mu \mathrm{M} / \mathrm{g})$ was detected at the end of the exponential growth phase and then remained constant till the end of the growth cycle. As a result, the action of some peptidases excreted into the medium during growth was canceled. Similarly, Yamada et al. (1984) reported that GSH was detectable in the control culture media of Candida tropicalis during growth. In addition, Yoon and Byun (2004) stated that L. casei HY 2782 showed high intracellular GSH levels reached $25.15 \mu \mathrm{M} / \mathrm{g}$ after $24 \mathrm{~h}$ of cultivation. As incubation proceeded, GSH levels tended to decrease until reached $5 \mu \mathrm{M} / \mathrm{g}$ after $72 \mathrm{~h}$

${ }^{1}$ http://www.softpedia.com/get/Science-AD/Clustal-X.shtml

TABLE 3 | Levels of the selected variables used in Box-Behnken for optimization of GSH production.

\begin{tabular}{lccc}
\hline Variables & $\mathbf{- 1}$ & $\mathbf{0}$ & $\mathbf{+ 1}$ \\
\hline Amino acids $(\%)$ & 0.0125 & 0.025 & 0.05 \\
Temperature $\left({ }^{\circ} \mathrm{C}\right)$ & 35 & 40 & 45 \\
Urea $(\%)$ & 0.02 & 0.1 & 0.5
\end{tabular}

TABLE 4 | Box-Behnken design of GSH production by L. plantarum as influenced by amino acids, temperature, and urea.

\begin{tabular}{lrrrrr}
\hline Trail no. & $\begin{array}{c}\text { Precursor } \\
\text { amino acids }\end{array}$ & Temperature & Urea & $\begin{array}{c}\text { Experimental } \\
\text { GSH }(\boldsymbol{\mu} \mathbf{M} / \mathbf{g})\end{array}$ & $\begin{array}{c}\text { Predicted } \\
\text { GSH }\end{array}$ \\
\hline 1 & 0 & -1 & -1 & 82.34 & 108.61 \\
2 & 0 & 1 & -1 & 129.01 & 110.84 \\
3 & 0 & -1 & 1 & 156.77 & 174.94 \\
4 & 0 & 1 & 1 & 194.51 & 168.25 \\
5 & -1 & -1 & 0 & 239.01 & 215.41 \\
6 & -1 & 1 & 0 & 305.76 & 326.59 \\
7 & 1 & -1 & 0 & 550.02 & 529.19 \\
8 & 1 & 1 & 0 & 389.93 & 413.53 \\
9 & -1 & 0 & -1 & 426.33 & 423.67 \\
10 & -1 & 0 & 1 & 512 & 517.43 \\
11 & 1 & 0 & -1 & 661.35 & 655.92 \\
12 & 1 & 0 & 1 & 683.24 & 685.90 \\
13 & 0 & 0 & 0 & 1599.06 & 1599.06
\end{tabular}




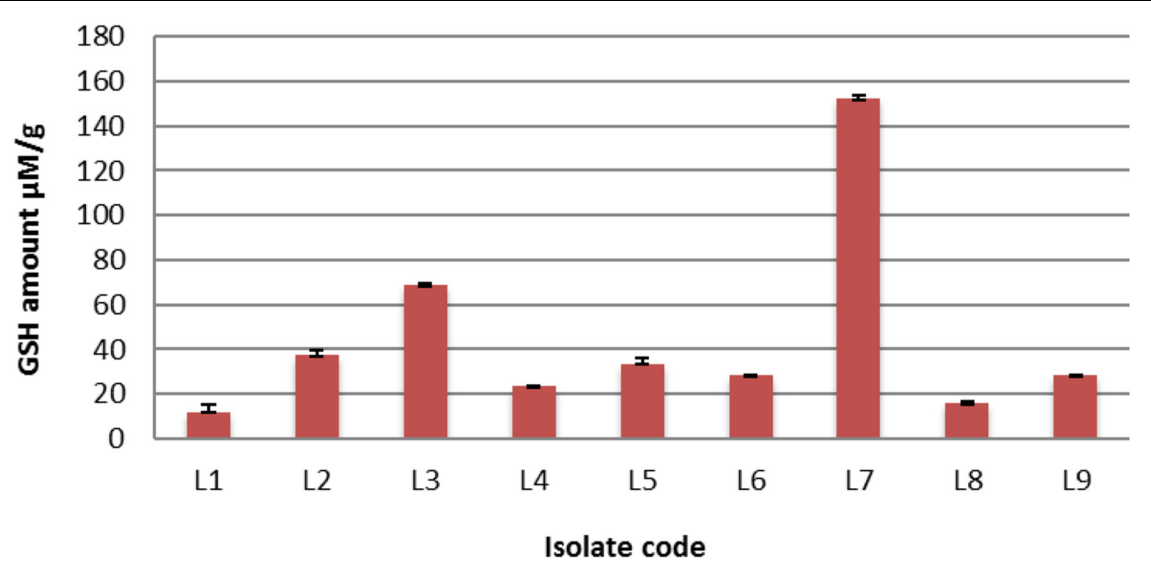

FIGURE 1 | The detected quantities of reduced glutathione (GSH) among different Lactobacillus plantarum isolates.

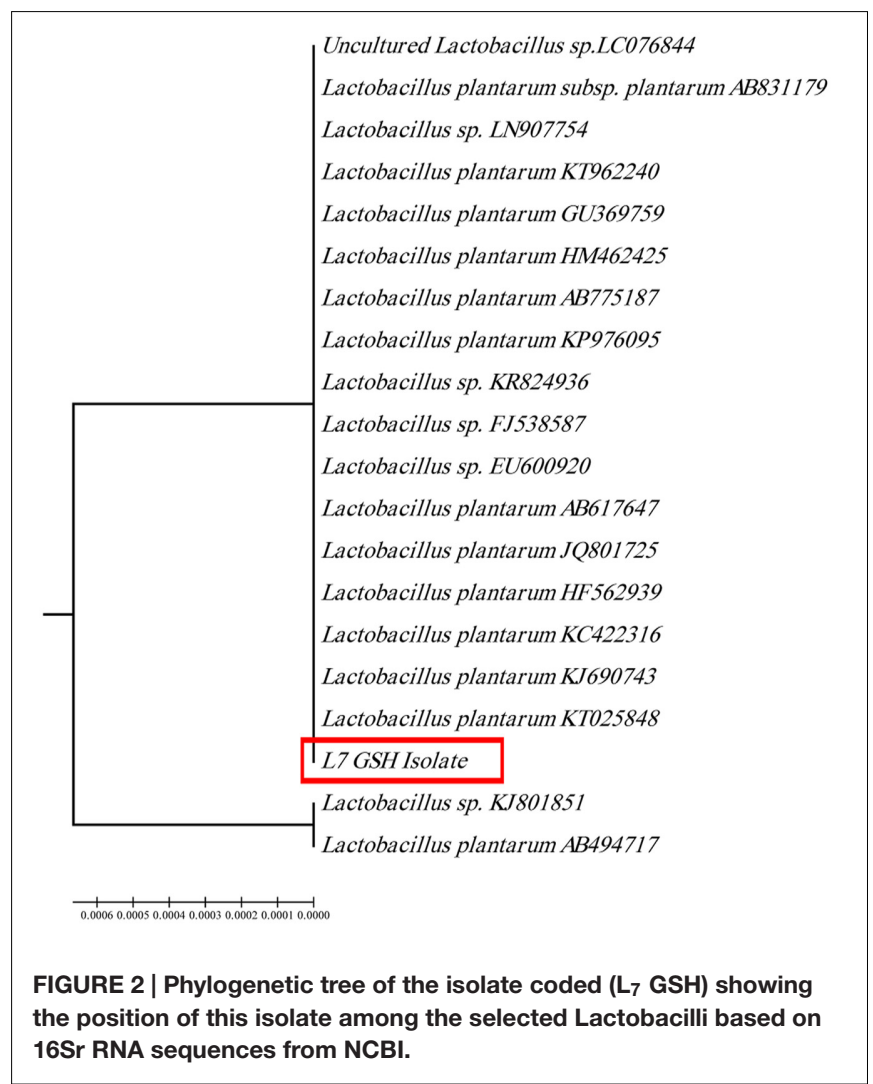

suggesting synthesis and release of certain peptidases into the medium.

The ultimate target of the biotechnological production of GSH is to achieve a high total GSH concentration through increasing the intracellular GSH content and cell density (Li et al., 2004). This could be achieved through selection of certain nutrient components in the culture media. It was reported that the best nitrogen sources increased the growth rate of $S$. cerevisiae were peptone and yeast extract. Moreover, their presence in the media enhanced the GSH productivity (Liu

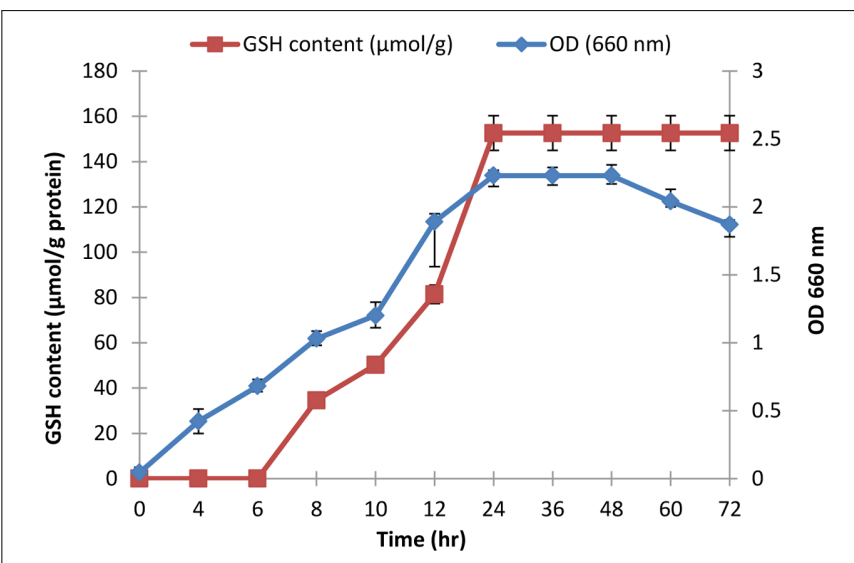

FIGURE 3 | Time-course of glutathione production by L. plantarum along with the biomass.

et al., 1999). Additionally, Shimizu et al. (1991) mentioned that the use of glucose as a sole carbon source at $1.5 \%$ was associated with marked increase in the biomass of $S$. cerevisiae as well as the GSH production. Furthermore, $0.15 \%$ magnesium sulfate was foremost important salt that could stimulate GSH production and cell growth. Lee et al. (2010) reported similar effect for magnesium sulfate on L. acidophilus A12. In the present work, all the above media components were already included in MRS in addition to other ingredients that are sufficient to enhance the cell density and GSH productivity. That is why we used MRS broth as a basal medium in our study. Yoon and Byun (2004) studied the relationship between the type of the media and the cellular GSH levels in L. casei HY 2782 and they found significant high GSH levels when MRS was used.

In preliminary experiments, we evaluated the effects of different separate stressful factors on the GSH production by $\mathrm{L}_{7}$ isolate as well as its biomass. We found that $0.1 \%$ ammonium persulfate, $2 \% \mathrm{MgCl}_{2}, 0.5 \% \mathrm{EDTA}, 2 \% \mathrm{CaCl}_{2}$, and $1 \% \mathrm{ZnSO}_{4}$ and $\mathrm{pH} 4$ decreased the production of GSH with slight decrease 


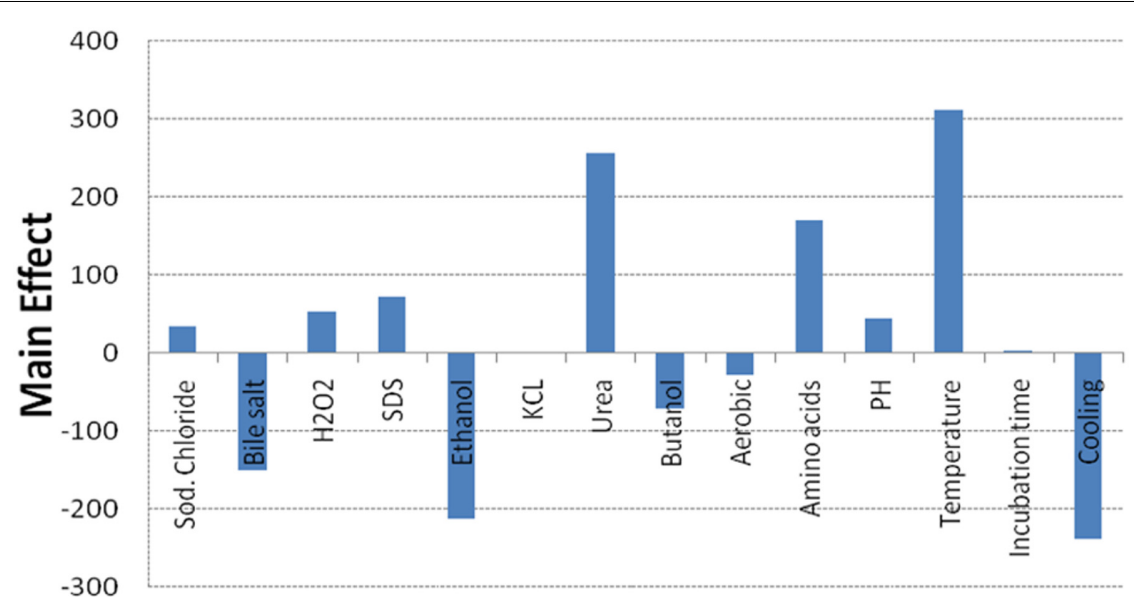

\section{Variables}

FIGURE 4 | Effect of culture conditions on the GSH production by L. plantarum isolate based on Plackett-Burman design results.

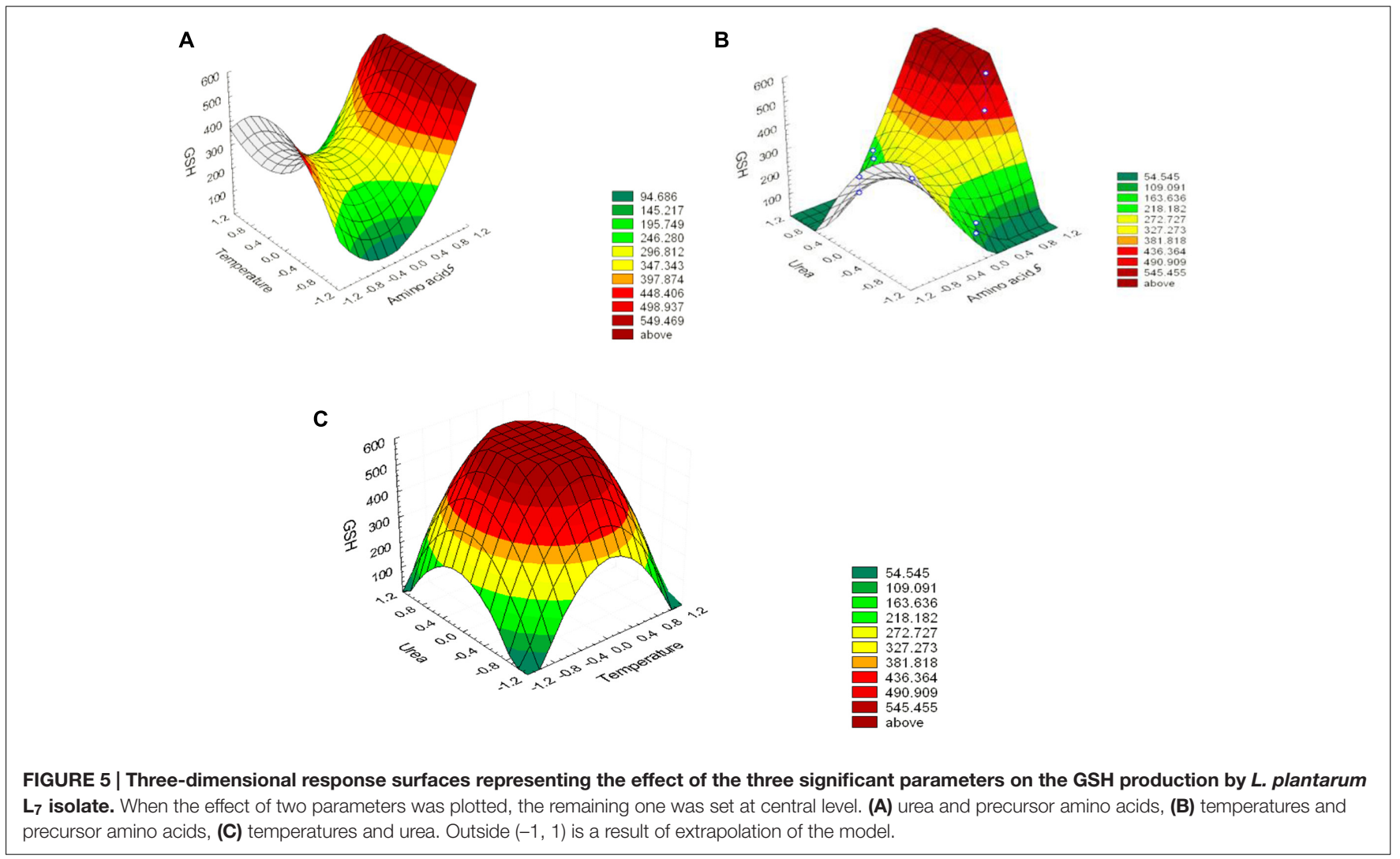

or no effect on the cell density when they were added to the basal medium. On the other hand, $0.5 \%$ bile salt, cooling at $4{ }^{\circ} \mathrm{C}$ following incubation, $5 \% \mathrm{NaCl}, \mathrm{pH} 8,0.05 \% \mathrm{SDS}, 0.025 \% \mathrm{H}_{2} \mathrm{O}_{2}$, $1 \%$ butanol, $1 \%$ urea, $2 \%$ ethanol, and $1 \%$ precursor amino acids increased GSH production with enhanced survival or no effect on the biomass compared to the control (preliminary data not shown). It was reported that $L$. plantarum from different niches could tolerate osmotic, oxidative, acid, alkaline, detergent and starvation stressors with a probability of stress-induced GSH production (Milesi et al., 2008; Pophaly et al., 2012). Cells of Lc. lactis subspecies cremoris SK11 presented 30\% higher GSH levels when incubated under aerobic conditions (Li et al., 2003). Additionally, Zhang et al. (2009) studied osmoadaptation by $L c$. lactis and they found that it was able to resist up to $5 \mathrm{M} \mathrm{NaCl}$ upon supplementation of GSH. Although cold stress decreased the levels of GSH produced by bacterial cells, supplementation 
of GSH to the medium could replenish the loss (Zhang et al., 2010). Furthermore, synthesis and accumulation of GSH by lactic acid bacteria as well as yeast could be correlated to their ability to combat reactive oxygen species such as $\mathrm{H}_{2} \mathrm{O}_{2}$ (Ubiyvovk et al., 2011; Pophaly et al., 2012). Accordingly, we decided to use a statistically based experimental design (Plackett-Burman) to screen for significant variables, among the above mentioned, influencing GSH production by the L. plantarum $\left(\mathrm{L}_{7}\right)$ isolate. In addition, levels of the significant variables were further optimized using Box-Behnken design.

Regarding the results of the Plackett-Burman design, there was a variation in the amount of GSH produced upon applying different trials of the design matrix as shown in Table 2 . It ranged between 122 and $1338 \mu \mathrm{M} / \mathrm{g}$. The main effects of the tested variables on GSH were calculated and illustrated in Figure 4. It showed that sodium chloride (5\%), hydrogen peroxide $(0.05 \%)$, sodium dodecyl sulfate $(0.05 \%)$, urea $(0.1 \%)$, precursor amino acids $(0.05 \%)$, temperature $\left(40^{\circ} \mathrm{C}\right)$, incubation time $(24 \mathrm{~h})$ and $\mathrm{pH} 8$ stimulated the GSH production. Among these, the most significant variables increasing the productivity were $0.05 \%$ precursor amino acids, $0.1 \%$ urea and incubation at $40^{\circ} \mathrm{C}$. Liang et al. (2008) reported that addition of the three precursor amino acids (glutamic acid $37 \mathrm{mM}$, glycine $35 \mathrm{mM}$, cysteine $32 \mathrm{mM}$ ) to the culture media of C. utilis enhanced the glutathione production dramatically. Springael and Penninckx (2003), reported that urea was an important nitrogenous source for $S$. cerevisiae growth as well as a strong oxidizing agent that was able to stimulate GSH production at a concentration of $0.1 \%$. Additionally, the optimal temperatures for cell growth and glutathione production were different. Many researchers have tried to improve the microbial production of glutathione through temperature adjustment (Shimizu et al., 1991; Alfafara et al., 1992; Li et al., 1998; Wei et al., 2003). In the present work, the quality of fitting model equation was determined with an $R^{2}$ of 0.8353 . The model equations for the GSH yield: $\mathrm{Y}_{\mathrm{GSH}}=537.3125+169.650611210532$ (precursor amino acids $)+310.851847691976$ (temperature $)+254.802687529275$ (urea).

In the present work, Box-Behnken design determined three levels for each significant independent variable that could optimize GSH production as presented in Table 3. The experimental results showed GSH levels that were nearly predicted and the highest amount produced was $1599.06 \mu \mathrm{M} / \mathrm{g}$ as recorded in Table 4. Masip et al. (2006) reported that L. lactis transformed with a plasmid expressing Escherichia coli gsh A and $g s h B$ genes resulted in a high intracellular GSH concentration, up to $140 \mathrm{mM}$, following addition of $5 \mathrm{mM}$ L-cysteine. In our study, the Box-Behnken design showed produced GSH levels of $160 \mathrm{mM}$, which is the highest concentration ever reported for a bacterial system, particularly because it was obtained by endogenous production and not transformation.

The effect of the amino acid precursors, temperature and urea on GSH production was represented as surface plots as shown in Figure 5. These plots were generated to study the effects of the three significant parameters on the GSH yield as a function of two factors while the remaining variable was set at its zero level. It was obvious from the plots that GSH yield was sensitive to alterations in the test variables. Significant increase in the GSH yield was observed due to the combined effect of urea and precursor amino acids (Figure 5B), and urea and temperature (Figure 5C). However, the interaction between precursor amino acids and temperature (Figure 5A) was relatively less significant which was consistent with the conclusion of Wen et al. (2005) and Liang et al. (2008). Glutamic acid is a primary metabolite that could be synthesized by $L$. plantarum and replenish the requirement for GSH production and this might explain why the interaction between precursor amino acids and temperature was comparatively less significant (Zareian et al., 2012). The optimal levels of the three components obtained from the maximum point of the polynomial model were found to be amino acids $(0.0281 \%)$, urea $(0.1916 \%)$, and temperature $40^{\circ} \mathrm{C}$. Following data analysis, the composition of the optimized medium was MRS broth supplemented with $\mathrm{NaCl}(5 \%), \mathrm{H}_{2} \mathrm{O}_{2}(0.05 \%)$, SDS $(0.05 \%)$, precursor amino acids $(0.0281 \%)$, and urea $(0.1916 \%)$. The $\mathrm{pH}$ of the media was adjusted to 8 and incubated for $24 \mathrm{~h}$ at $40^{\circ} \mathrm{C}$. Verification of the model was done by conducting the experiment using the optimized medium. It resulted in GSH yield of $1610.22 \mu \mathrm{M} / \mathrm{g}$ which is close to the predicted response $(1599.06 \mu \mathrm{M} / \mathrm{g})$ indicating the validity of the model. GSH production in the optimized medium was 10 -fold (851\%) higher than what was produced using the basal medium alone. Alfafara et al. (1992) reported that the addition of amino acids was required for GSH production even though sugar was the major substrate consumed in fermentative production of GSH. Furthermore, a stimulatory effect of $9 \mathrm{mM} \mathrm{L-cysteine} \mathrm{on} \mathrm{GSH}$ production was observed in recombinant E. coli (Li et al., 1998), where the total GSH concentration and the intracellular GSH content increased by 40 and $100 \%$, respectively. In addition to L-cysteine, several other substrates were found to stimulate GSH production (Liang et al., 2008), ethanol on S. cerevisiae (1.4-fold increase; Kyowa Hakko Kogyo Co., Ltd, 1984), amino acids supplements on S. cerevisiae (3.4-fold increase; Watanabe et al., 1986), p-amino benzoic acid on Hansenula capsuleita (94\% increase; Kinoshita et al., 1986), and sodium lactate on S. cerevisiae ( $82 \%$ increase; Hirakawa et al., 1985). Additionally, Liang et al. (2009) found that lower $\mathrm{pH}$ value favored the growth of C. utilis but decreased GSH production, whereas higher $\mathrm{pH}$ values promoted GSH production and inhibited cell growth. Accordingly, they altered the $\mathrm{pH}$ and found that to be effective. In our study, adjusting $\mathrm{pH}$ as high as 8 promoted GSH production as shown in Figure 4. In addition, the selected strain $\mathrm{L}_{7}$ showed resistance to $\mathrm{pH} 8$ and reached a high OD (data not shown). On the other hand, Zhang et al. (2007) and Ubiyvovk et al. (2011) reported that low pH values resulted in higher GSH levels.

\section{CONCLUSION}

A GSH over-producing food-grade microorganism such as L. plantarum (KU720558) was previously isolated and used in the present study. Fermentative production of GSH was successfully optimized through subjecting the strain to a matrix of stressors 
using Plackett-Burman and Box-Behnken statistical designs. Our study showed 10 -fold increase (851\%) in the GSH yield. This design offers significant opportunity for GSH production by L. plantarum recommending the use of the optimized media and conditions.

\section{REFERENCES}

Abdel-Fattah, Y. R., Saeed, H. M., Gohar, Y. M., and El-Baz, M. A. (2005). Improved production of Pseudomonas aeruginosa uricase by optimization of process parameters through statistical experimental designs. Process Biochem. 40, 1707-1714. doi: 10.1016/j.procbio.2004.06.048

Alfafara, C., Miura, K., Shimizu, H., Shioya, S., and Suga, K. (1992). Cysteine addition strategy for maximum glutathione production in fed-batch culture of Saccharomyces cerevisiae. Appl. Microbiol. Biotechnol. 37, 141-146. doi: 10.1007/ BF00178160

Ali, S. M., Omar, S. H., and Soliman, N. A. (2013). Co-production of cellulase and xylanase enzymes by thermophilic Bacillus subtilis 276NS. Int. J. Biotechnol. Wellness Ind. 2, 65-74.

Al-Madboly, L. A., and Abdullah, A. K. (2015). Potent antagonistic activity of Egyptian Lactobacillus plantarum against multiresistant and virulent food-associated pathogens. Front. Microbiol. 6:347. doi: 10.3389/fmicb. 00347

Beutler, E., Duron, O., and Kelly, B. M. (1963). Improved method for the determination of blood glutathione. J. Lab. Clin. Med. 61, 882-890.

Box, G. E., and Behnken, D. W. (1960). Some new three level designs for the study of quantitative variables. Technometrics 2, 455-475. doi: 10.1080/00401706. 1960.10489912

Chi-Hsien, L., Chin-Fa, H., and Chii-Cherng, L. (1999). Medium optimization for glutathione production by Saccharomyces cerevisiae. Process Biochem. 34, 17-23. doi: 10.1016/S0032-9592(98)00055-7

Farr, B. S., and Kogoma, T. (1991). Oxidative stress responses in Escherichia coli and Salmonella typhimurium. Microbiol. Rev. 55, 561-585.

Fernandes, L., and Steele, J. L. (1993). Glutathione content of lactic acid bacteria. J. Dairy Sci. 76, 1233-1242. doi: 10.3168/jds.S0022-0302(93) 77452-4

Halliwell, B., and Gutteridge, J. M. C. (1992). Biologically relevant metal iondependent hydroxyl radical generation. FEBS Lett. 307, 108-112. doi: 10.1016/ 0014-5793(92)80911-Y

Hirakawa, K., Nomura, K., and Kato, M. (1985). Lactic acid for high yield glutathione production by yeasts. JP 60244284 .

Kinoshita, K., Machida, M., Oka, S., Yamamoto, Y., and Tomikanehara, H. (1986). Manufacture of yeast cells containing high glutathione. JP 61192282. doi: 10.1016/j.nut.2012.11.012

Kyowa Hakko Kogyo Co., Ltd (1984). Yield increase in glutathione produced by yeasts. JP 59034899.

Lee, N. K., Park, Y.-L., Ga, J. C., Hyo-Ih, C., and Hyun-Dong, P. (2010). Medium optimization for the production of probiotic Lactobacillus acidophilus A12 using response surface methodology. Korean J. Food Sci. Anim. Resour. 30, 359-364. doi: 10.5851/kosfa.2010.30.3.359

Li, Y., Chen, J., Zhou, N., Fu, W., Ruan, W., and Lun, S. (1998). The effect of environmental conditions and glucose feeding in shaking flask on glutathione (GSH) production. Chin. J. Biotechnol. 14, 85-91.

Li, Y., Hugenholtz, J., Abee, T., and Molenaar, D. (2003). Glutathione protects Lactococcus lactis against oxidative stress. Appl. Environ. Microbiol. 69, 5739-5745. doi: 10.1128/AEM.69.10.5739-5745.2003

Li, Y., Wei, G., and Chen, J. (2004). Glutathione: a review on biotechnological production. Appl. Microbiol. Biotechnol. 66, 233-242. doi: 10.1007/s00253-0041751-y

Liang, G., Liao, X., Du, G., and Chen, J. (2008). Elevated glutathione production by adding precursor amino acids coupled with ATP in high cell density cultivation of Candida utilis. J. Appl. Microbiol. 105, 1432-1440. doi: 10.1111/j.1365-2672. 2008.03892.x

Liang, G., Wang, B., Xie, J., and Mo, Y. (2009). Novel pH control strategy for glutathione overproduction in batch cultivation of Candida utilis. Afr. J. Biol. $8,6337-6345$.

\section{AUTHOR CONTRIBUTIONS}

LA-M conceived the experiments, LA-M, SA, and EK conducted the experiments, SA analyzed the results. All authors reviewed the manuscript.

Liu, C. H., Hwang, C. F., and Liao, C. C. (1999). Medium optimization for glutathione production by Saccharomyces cerevisiae. Process Biochem. 34, 17-23. doi: 10.1016/S0032-9592(98)00055-7

Masip, L., Veeravalli, K., and Georgiou, G. (2006). The many faces of glutathione in bacteria. Antioxid. Redox Signal. 8, 753-762. doi: 10.1089/ars.2006.8.753

Milesi, M. M., McSweeney, P. L. H., and Hynes, E. R. (2008). Viability and contribution to proteolysis of an adjunct culture of Lactobacillus plantarum in two model cheese systems: cheddar cheese-type and soft-cheese type. J. Appl. Microbiol. 105, 884-892. doi: 10.1111/j.1365-2672.2008.03813.x

Murata, K., and Kimura, A. (1982). Cloning of a gene responsible for the biosynthesis of glutathione in Escherichia coli B. Appl. Environ. Microbiol. 44, 1444-1448.

Olson, D. W., and Aryana, K. J. (2012). Effect of Prebiotics on Lactobacillus acidophilus growth and resulting $\mathrm{pH}$ changes in skim milk and a model peptone system. J. Microb. Biochem. Technol. 4, 121-125. doi: 10.4172/19485948.1000081

Pastore, A., Federici, G., Bertini, E., and Piemonte, F. (2003). Analysis of glutathione: implication in redox and detoxification. Clin. Chim. Acta 333, 19-39. doi: 10.1016/S0009-8981(03)00200-6

Plackett, R. L., and Burman, J. P. (1946). The design of optimum multifactorial experiments. Biometrika 33, 305-325. doi: 10.1093/biomet/ 33.4.305

Pophaly, S. D., Singh, R., Pophaly, S. D., Kaushik, J. K., and Tomar, S. K. (2012). Current status and emerging role of glutathione in food grade lactic acid bacteria. Microb. Cell Fact. 11:114. doi: 10.1186/1475-285911-114

Rathnasabapathy, C. S., Basha, S. M., and Dhanasekar, R. (2009). Enhanced production of glutathione from Candida utilis using Palm Jaggery. Int. J. Chemtech Res. 1, 1137-1144.

Shimizu, H., Araki, K., Shioya, S., and Suga, K. (1991). Optimal production of glutathione by controlling the specific growth rate of yeast in fed-batch culture. Biotechnol. Bioeng. 38, 196-205. doi: 10.1002/bit.260380212

Springael, J.-Y., and Penninckx, M. J. (2003). Nitrogen-source regulation of yeast gamma-glutamyl transpeptidase synthesis involves the regulatory network including the GATA zinc-finger factors Gln3, Nil1/Gat1 and Gzf3. Biochem. J. 371(Pt 2), 589-595. doi: 10.1042/BJ20021893

Steppan, D., Werner, J., and Yeater, B. (1999). Essential Regression and Experimental Design in MS Excel-Free, user Friendly Software Package for doing Multiple Linear Regression, Step-Wise Regression, Polynomial Regression, Model Adequacy Checking and Experimental Design in MS Excel. Available at: http://www.oocities.org/siliconvalley/network/1032/

Ubiyvovk, V. M., Vladimir, M. A., Alexander, Y. M., Hyun, A. K., and Andriy, A. S. (2011). Optimization of glutathione production batch and fed-batch cultures by the wild-type and recombinant strains of methylotrophic yeast Hansenula polymorph DL-1. BMC Biotechnol. 11:8. doi: 10.1186/1472-6750-11-18

Watanabe, K., Yamano, Y., Murata, K., and Kimura, A. (1986). Glutathione production by Escherichia coli cells with hybrid plasmid containing tandemly polymerized genes for glutathione synthetase. Appl. Microbiol. Biotechnol. 24, 375-378. doi: 10.1007/BF00294593

Wei, G., Li, Y., Du, G., and Chen, J. (2003). Application of a two stage temperature control strategy for enhanced glutathione production in the batch fermentation by Candida utilis. Biotechnol. Lett. 25, 887-890. doi: 10.1023/A:102403450 8136

Wen, S. H., Zhang, T., and Tan, T. W. (2005). Optimization of the amino acid composition in glutathione fermentation. Process Biochem. 40, 3474-3479. doi: $10.1016 /$ j.procbio.2005.02.027

Wiederholt, K. M., and Steele, J. L. (1994). Glutathione accumulation in Lactococci. J. Dairy Sci. 77, 1183-1188. doi: 10.3168/jds.S0022-0302(94)77056-9

Yamada, Y., Tani, Y., and Kamihara, T. (1984). Production of extracellular glutathione by Candida tropicalis Pk233. J. Gen. Microbiol. 130, 3275-3278. 
Yoon, Y. H., and Byun, J. R. (2004). Occurrence of glutathione sulphydryl (GSH) and antioxidant activities in probiotic Lactobacillus spp. Asian Australas. J. Anim. Sci. 17, 1582-1585. doi: 10.5713/ajas.2004. 1582

Zareian, M., Ebrahimpour, A., Abu Bakar, F., Mohamed, A. K. S., Forghani, B., Ab-Kadir, M. S. B., et al. (2012). A glutamic acid-producing lactic acid bacteria isolated from malaysian fermented foods. Int. J. Mol. Sci. 13, 5482-5497. doi: 10.3390/ijms13055482

Zhang, J., Fu, R.-Y., Hugenholtz, J., Li, Y., and Chen, J. (2007). Glutathione protects Lactococcus lactis against acid stress. Appl. Environ. Microbiol. 73, 5268-5275. doi: 10.1128/AEM.02787-06

Zhang, W. Y., Yu, D. L., Sun, Z. H., Airideng, C., Hu, S. N., Meng, H., et al. (2009). Preliminary analysis of glutathione S-transferase homolog from Lactobacillus casei Zhang. Ann. Microbiol. 59, 727-731. doi: 10.1007/BF0317 9215
Zhang, Y., Zhu, Y., Mao, S., and Li, Y. (2010). Proteomic analyses to reveal the protective role of glutathione in resistance of Lactococcus lactis to osmotic stress. Appl. Environ. Microbiol. 76, 3177-3186. doi: 10.1128/AEM. 02942-09

Conflict of Interest Statement: The authors declare that the research was conducted in the absence of any commercial or financial relationships that could be construed as a potential conflict of interest.

Copyright (c) 2017 Al-Madboly, Khedr and Ali. This is an open-access article distributed under the terms of the Creative Commons Attribution License (CC BY).

The use, distribution or reproduction in other forums is permitted, provided the original author(s) or licensor are credited and that the original publication in this journal is cited, in accordance with accepted academic practice. No use, distribution or reproduction is permitted which does not comply with these terms. 